University of Nebraska - Lincoln

DigitalCommons@University of Nebraska - Lincoln

Faculty Papers and Publications in Animal

Science

Animal Science Department

$12-11-2002$

\title{
Estimates of genetic parameters and genetic change for reproduction, weight, and wool characteristics of Columbia sheep
}

\author{
Kathryn J. Hanford \\ University of Nebraska, kathy.hanford@unl.edu \\ L. Dale Van Vleck \\ University of Nebraska-Lincoln, dvan-vleck1@unl.edu
}

G. D. Snowder

USDA, ARS, U.S. Sheep Experimental Station, Dubois, ID 83423

Follow this and additional works at: https://digitalcommons.unl.edu/animalscifacpub

Part of the Animal Sciences Commons

Hanford, Kathryn J.; Van Vleck, L. Dale; and Snowder, G. D., "Estimates of genetic parameters and genetic change for reproduction, weight, and wool characteristics of Columbia sheep" (2002). Faculty Papers and Publications in Animal Science. 230.

https://digitalcommons.unl.edu/animalscifacpub/230

This Article is brought to you for free and open access by the Animal Science Department at DigitalCommons@University of Nebraska - Lincoln. It has been accepted for inclusion in Faculty Papers and Publications in Animal Science by an authorized administrator of DigitalCommons@University of Nebraska - Lincoln. 


\title{
Estimates of genetic parameters and genetic change for reproduction, weight, and wool characteristics of Columbia sheep ${ }^{1}$
}

\author{
K. J. Hanford ${ }^{* 2}$, L. D. Van Vleck $\dagger$, and G. D. Snowder $\ddagger^{3}$ \\ *Department of Animal Science, University of Nebraska, Lincoln 68583-0908; \\ $\nmid$ USDA, ARS, U.S. Meat Animal Research Center, Lincoln, NE 68583-0908; and \\ †USDA, ARS, U.S. Sheep Experimental Station, Dubois, ID 83423
}

\begin{abstract}
Genetic parameters from both singletrait and bivariate analyses for prolificacy, weight and wool traits were estimated using REML with animal models for Columbia sheep from data collected from 1950 to 1998 at the U.S. Sheep Experiment Station (USSES), Dubois, ID. Breeding values from both singletrait and seven-trait analyses calculated using the parameters estimated from the single-trait and bivariate analyses were compared with respect to genetic trends. Number of observations were 31,401 for litter size at birth and litter size at weaning, 24,741 for birth weight, 23,903 for weaning weight, 29,572 for fleece weight and fleece grade, and 2,449 for staple length. Direct heritability estimates from single-trait analyses were 0.09 for litter size at birth, 0.06 for litter size at weaning, 0.27 for birth weight, 0.16 for weaning weight, 0.53 for fleece weight, 0.41 for fleece grade, and 0.55 for staple length. Estimate of direct genetic correlation between litter size at birth and weaning was 0.84 and between birth and weaning weights was 0.56 . Estimate of genetic correlation between fleece weight and staple length was positive (0.55) but negative between fleece weight and fleece
\end{abstract}

grade $(-0.47)$ and between staple length and fleece grade (-0.70). Estimates of genetic correlations were positive but small between birth weight and litter size traits and moderate and positive between weaning weight and litter size traits. Fleece weight was lowly and negatively correlated with both litter size traits. Fleece grade was lowly and positively correlated with both litter size traits, while staple length was lowly and negatively correlated with the litter size traits. Estimates of correlations between weight traits and fleece weight were positive and low to moderate. Estimates of correlations between weight traits and fleece grade were negative and small. Estimates of correlations between staple length and birth weight (0.05) and weaning weight were small (-0.04). Estimated breeding values averaged by year of birth from both the singletrait and multiple-trait analyses for the prolificacy and weight traits increased over time, but were unchanged for the wool traits. Estimated changes in breeding values over time did not differ substantially for singletrait and multiple-trait analyses, except for traits highly correlated with another trait that was responding to selection.

Key Words: Breeding Value, Genetic Correlation, Heritability, Litter Size, Prolificacy, Weaning Weight

(C2002 American Society of Animal Science. All rights reserved.

J. Anim. Sci. 2002. 80:3086-3098

\section{Introduction}

Few selection studies have been conducted with dual-purpose Western range sheep in the United States, and even fewer of these can be considered longterm studies. Sakul et al. (1999) reported slight improvement in litter size and 120-d weight over a 30 yr period for grade Targhee sheep, in a range environ-

\footnotetext{
${ }^{1}$ Published as paper no. 13626, Journal Ser., Nebraska Agric. Res. Div., Univ. of Nebraska, Lincoln 68583-0908.

${ }^{2}$ Correspondence: A218 Animal Science, (phone: 402-472-6409; fax: 402-472-6362; E-mail: khanford2@unl.edu).

${ }^{3}$ Current address: P.O. Box 166, Clay Center, NE 68933.

Received February 4, 2002.

Accepted July 22, 2002.
}

ment. However, they concluded that the response represented a potentially significant economic advantage. Ercanbrack and Knight (1998) reported phenotypic trends and genetic gains for a 12-yr period for four breeds of range sheep. They showed that selection solely for litter weight of lamb weaned substantially increased lamb production with only minor penalties in wool production. Burfening et al. (1993) estimated genetic change in reproductive rate in Rambouillet sheep raised in a range environment. Their selection for $18 \mathrm{yr}$ was based on a reproductive index of dam's total lifetime lambs born/(age in years - 1). Their results indicated that the reproductive index did respond to selection. Lasslo et al. (1985) reported genetic improvement in dual-purpose Targhee sheep selected for weaning weight over $20 \mathrm{yr}$ for both a range environ- 
Table 1. Number of records, animals with records, sires and dams of animals with records, years of records, and unadjusted means and standard deviations (SD) of prolificacy, weight, and wool traits

\begin{tabular}{|c|c|c|c|c|c|c|}
\hline Trait & Records & $\begin{array}{l}\text { Animals with } \\
\text { records }\end{array}$ & Sires & Dams & $\begin{array}{l}\text { Years of } \\
\text { record }\end{array}$ & Mean \pm SD \\
\hline \multicolumn{7}{|l|}{ Prolificacy traits (trait of ewe) } \\
\hline Litter size at weaning ${ }^{\mathrm{a}}$ & 31,401 & 8,379 & 916 & 4,152 & $1950-1998$ & $0.91 \pm 0.72$ \\
\hline \multicolumn{7}{|l|}{ Weight traits (trait of lamb) } \\
\hline Birth weight, kg & 24,741 & 24,741 & 1,020 & 6,385 & $1950-1998$ & $4.89 \pm 0.86$ \\
\hline Fleece weight, kg & 29,572 & 7,974 & 911 & 4,106 & $1953-1998$ & $5.31 \pm 1.03$ \\
\hline Fleece grade, U.S. spinning count & 29,572 & 7,974 & 911 & 4,106 & $1953-1998$ & $55.9 \pm 3.8$ \\
\hline Staple length, $\mathrm{cm}$ & 2,449 & 2,449 & 226 & 1,340 & $1977-1991$ & $9.23 \pm 1.18$ \\
\hline
\end{tabular}

ancludes records from all ewes exposed to a ram at breeding and present at lambing.

ment and an environment with a higher plane of nutrition.

The main objective of this study was to document genetic trends in production traits of the Columbia, a dual-purpose breed of sheep at the U.S. Sheep Experiment Station (USSES), Dubois, ID, over a 49-yr period (1950 to 1998), where selection was based on weaning performance under range conditions. The production traits examined included prolificacy, weight, and wool traits. A secondary objective was to compare genetic trends estimated from single- and multi-trait analyses.

\section{Materials and Methods}

\section{Animals and Management}

The Columbia breed was developed at the Wyoming Experiment Station at Laramie in 1912 from Rambouillet ewes bred to Lincoln rams and was moved to the USSES in 1916. From its inception, the Columbia breed has been maintained and included in a variety of selection projects at the USSES (Ercanbrack and Knight, 1981; 1998). The USSES has been a primary source of foundation breeding stock for the Columbia breed. This population of Columbia sheep represents the longest time span (49 yr) and the largest number of animals (approximately 31,000 lamb records) currently available for determining genetic parameters for the Columbia breed. Currently, few estimates of genetic parameters for the Columbia breed are available. Bromley et al. (2000) estimated genetic parameters using data from 1977 through 1996 from this population.

During the 48-yr period, the Columbia breed was subjected to different selection criteria generally related to increasing weaning weight. Selection favored wool and growth traits in the early years (approximately 1950 to 1969), then individual lamb weaning weight and litter size (from 1969 to 1976), then weaning weight of the lamb or total litter weight weaned of the ewe (from 1976 to 1998). A random bred control line was also maintained for many of these years. A total of six outside rams were introduced, all for the 1977 and 1978 breeding seasons. Lines have been rerandomized several times as new selection criteria were imposed on the flock. Rams in control lines that were superior for the selection traits were often used in the appropriate selection lines. The effect of selection could not be accounted for because of the rerandomization of breeding animals over the years of this study. The genetic trend in this flock may represent general selection emphasis of the American sheep industry over this time period for traits of economic importance.

The numbers of records per trait, as well as unadjusted means and standard deviations, are presented in Table 1. Ercanbrack and Knight (1998) previously described general management of the flock. Ewes were produced and managed as range ewes. Lambs were born under shed-lambing conditions primarily in April. Litters with more than two lambs born alive were reduced to two lambs by fostering excess lambs to other ewes or raising them as orphans. One or two $\mathrm{d}$ after lambing, ewes and lambs were moved to outside feedlots (mixing pens). Fifteen to $20 \mathrm{~d}$ after lambing, ewes and lambs were put into grazing bands and grazed on a sagebrush-grass, spring-fall range at elevations ranging from 1,600 to $1,700 \mathrm{~m}$. At approximately $75 \mathrm{~d}$ of age, bands were moved to a mountain summer range, where they grazed at elevations ranging from 2,000 to $2,900 \mathrm{~m}$. Weaning data were obtained on the summer range in August when the average lamb age was near $120 \mathrm{~d}$ and when ram lambs were removed from the flock. Ewes were trailed back to the spring-fall range in mid-September, where ewe lambs were removed and ewes were culled for unsoundness. Ewe lambs were bred at 7 mo of age to lamb as yearlings. Ewes were exposed to rams in single-sire pens in early November for $21 \mathrm{~d}$. The number of ewes per ram varied, with a breeding ratio of 20 to 30 ewes per ram for the selection lines and 12 to 18 ewes per ram for the control lines. After the initial breeding period, ewes were trailed to a winter range (approximately 1,600 to $1,700 \mathrm{~m}$ elevation) and exposed to Suffolk 
Table 2. Number of litters of ewes bred and present at lambing and unadjusted survival rates (\% of lambs born) at birth and weaning by type of birth

\begin{tabular}{lccc}
\hline \hline & & \multicolumn{2}{c}{ Survival } \\
\cline { 3 - 4 } Birth type & $\begin{array}{c}\text { Number of litters } \\
\text { (\% of total) }\end{array}$ & Birth & Weaning \\
\hline Nonpregnant & $4,392(14.0)$ & - & - \\
Singles & $14,545(46.3)$ & 88.9 & 73.8 \\
Twins & $11,695(37.2)$ & 94.0 & 71.8 \\
Triplets & $757(2.4)$ & 91.6 & 49.3 \\
Quadruplets & $12(0.1)$ & 75.0 & 25.0 \\
\hline
\end{tabular}

type rams for approximately $30 \mathrm{~d}$; lambs from these crossbreed matings were not included in the ewe's record. Ewes grazed the winter range until accumulating snow required management to move the ewes into feedlots, typically in mid-January. In the feedlots, ewes were fed a late-gestation ration through the lambing period.

Prolificacy Traits. Litter size at birth (number of lambs born per ewe exposed during single-sire pen matings) and litter size at weaning (number of lambs weaned per ewe exposed) were recorded for each ewe exposed and present at lambing. Only lambs born and raised by a ewe were included in litter size at weaning. A summary of the numbers of litters born, types of birth, and survival by type of birth is presented in Table 2. Lower survival rates of single born lambs compared to twin born lambs were likely due to the greater proportion of single born lambs being reared by younger ewes (Snowder et al., 2001). A summary of numbers of ewes by age, litter size at both birth and weaning, and survival by age of ewe is presented in Table 3.

Weight Traits. Birth weight (kilograms) was recorded for all lambs born alive. Only records from purebred lambs raised by their birth dam were included in analyses of weaning weight data. Weaning weight (kilograms) was adjusted to $120 \mathrm{~d}$ of age, using individual birth weight and average daily gain from birth to weaning.

Wool Traits. Greasy fleece weight (kilograms) and fleece grade (U.S. spinning count) were obtained annually at shearing in late May. Fleece grades were subjectively determined by certified graders according to U.S. wool grade standards (Pohle, 1963). Staple length (centimeters) was measured prior to shearing at midside without stretching the fiber. Staple length was primarily measured on lambs and rams only. Staple length data for ewe lambs were available from 1977 through 1991. Only wool data from ewes and ewe lambs with lambing records were included in these analyses.

\section{Statistical Analysis}

(Co)variance components for each trait were estimated from single-trait analyses using models de- scribed in Table 4. (Co)variance components between traits were estimated from two-trait analyses where the models described in Table 4 were combined with appropriate covariances between random effects in the model. Individual breeding values were estimated from single-trait analyses. Individual breeding values were also estimated from a seven-trait analysis, using the within trait co(variances) from single-trait analyses and between trait correlations from two-trait analyses. Means of estimated breeding values by year of birth were calculated from the seven-trait analysis and compared with the corresponding means of estimated breeding values from single-trait analyses.

\section{Single-Trait Analysis}

The single-trait linear model used was

$$
\mathbf{y}=\mathbf{X} \boldsymbol{\beta}+\mathbf{Z}_{\mathrm{a}} \mathbf{a}+\mathbf{Z}_{\mathrm{m}} \mathbf{m}+\mathbf{Z}_{\mathrm{p}} \mathbf{p}+\mathbf{e}
$$

where $\mathbf{y}$ is the vector of observations, $\boldsymbol{\beta}$ is the vector of fixed effects, $\mathbf{X}$ is a design matrix relating fixed effects to $\mathbf{y}, \mathbf{a}$ is a vector of additive genetic effects of animals, $\mathbf{m}$ is a vector of maternal genetic effects, $\mathbf{p}$ is a vector of permanent environmental effects corresponding to the ewes, with incidence matrices $\mathbf{Z}_{\mathrm{a}}, \mathbf{Z}_{\mathrm{m}}$, and $\mathbf{Z}_{\mathrm{p}}$ relating the effects to $\mathbf{y}$, and $\mathbf{e}$ is a vector of random residual effects. Nonadditive genetic effects were assumed not to exist.

Expected values and (co)variance structures for random effects were assumed to be $\mathrm{E}(\mathbf{y})=\mathbf{X} \boldsymbol{\beta}, \mathrm{E}(\mathbf{a})=\mathrm{E}(\mathbf{m})$ $=\mathrm{E}(\mathbf{p})=0, \operatorname{var}(\mathbf{a})=\mathbf{A} \sigma_{\mathrm{a}}^{2}, \operatorname{var}(\mathbf{m})=\mathbf{A} \sigma, \operatorname{var}(\mathbf{p})=\mathrm{I}_{\mathrm{p}} \sigma_{\mathrm{p}}^{2}$, $\operatorname{var}(\mathbf{e})=\mathrm{I}_{\mathrm{n}} \sigma_{\mathrm{e}}^{2}, \operatorname{cov}\left(\mathbf{a}, \mathbf{m}^{\prime}\right)=\mathrm{A} \sigma_{\mathrm{am}}$ and $\operatorname{cov}\left(\mathbf{p}, \mathbf{e}^{\prime}\right)=\operatorname{cov}\left(\mathbf{a}, \mathbf{p}^{\prime}\right)$ $=\operatorname{cov}\left(\mathbf{a}, \mathbf{e}^{\prime}\right)=0$, where $\mathbf{A}$ is the numerator relationship matrix, $\mathbf{I}_{\mathrm{p}}$ and $\mathbf{I}_{\mathrm{n}}$ are identity matrices with order equal to the number of ewes (p) and number of records (n), and $\sigma_{\mathrm{a}}^{2}, \sigma_{\mathrm{m}}^{2}, \sigma_{\mathrm{p}}^{2}$, and $\sigma_{\mathrm{e}}^{2}$ are the direct additive genetic, maternal additive genetic, permanent environmental, and residual components of variance, respectively, and $\sigma_{\mathrm{am}}$ is the covariance between direct and maternal additive genetic effects. The full model was used for the weight traits, while a reduced model with the maternal genetic effects removed was used for the prolificacy and wool traits. Because only yearling records were in the staple length analysis, the permanent environmental effect was not included in the model for staple length.

Fixed effects included in the model for the prolificacy traits were age of ewe in years at lambing (1 to 12) and year of lambing (1950 to 1998). Records of all ewes that were bred and present at lambing were included. Therefore, number of lambs at birth or at weaning could be zero. Analyses of litter size at birth included only parturitions that resulted from single-sire pen matings. Litter size at weaning included only lambs that resulted from single-sire pen matings that were present with their biological mother at weaning. Models for litter size at weaning included the fixed effect of foster code (1, if ewe did not raise a foster lamb; 2 , 
Table 3. Number of litters and unadjusted litter sizes of ewes bred and present at lambing and survival rates (\% of lambs born) at birth

and weaning $(120 \mathrm{~d})$ by age of ewe

\begin{tabular}{|c|c|c|c|c|c|c|}
\hline \multirow[b]{2}{*}{ Age (yr) } & \multirow{2}{*}{$\begin{array}{c}\text { Number of ewes } \\
(\% \text { of total })\end{array}$} & \multirow{2}{*}{$\begin{array}{l}\text { Number } \\
\text { of litters }\end{array}$} & \multicolumn{2}{|c|}{ Litter size ${ }^{a}$} & \multicolumn{2}{|c|}{ Survival } \\
\hline & & & Birth & Weaning & Birth & Weaning \\
\hline 1 & $3,344(10.7)$ & 1,447 & 0.52 & 0.30 & 88.2 & 60.7 \\
\hline 2 & $7,274(23.2)$ & 6,458 & 1.15 & 0.78 & 88.3 & 68.7 \\
\hline 3 & $6,215(19.8)$ & 5,620 & 1.33 & 0.96 & 89.7 & 72.8 \\
\hline $4-6$ & $11,515(36.7)$ & 10,668 & 1.50 & 1.12 & 93.5 & 75.8 \\
\hline$\geq 7$ & $3,053 \quad(9.7)$ & 2,816 & 1.50 & 1.04 & 93.4 & 71.4 \\
\hline
\end{tabular}

${ }^{\text {a} I n c l u d e s ~ r e c o r d s ~ f r o m ~ a l l ~ e w e s ~ e x p o s e d ~ t o ~ a ~ r a m ~ a t ~ b r e e d i n g ~ a n d ~ p r e s e n t ~ a t ~ l a m b i n g . ~}$

if ewe did raise a foster lamb). Foster lamb records were not included in the record of either the birth dam or the foster dam for litter size at weaning.

The model for birth weight also included the fixed effect of type of birth (1 to 4), while the model for weaning weight included the fixed effect of type of birth and rearing. One of eight types of birth and rearing combinations was assigned to each lamb to account for a lamb born as a single, twin, triplet, or quadruplet, and reared as a single, twin, or triplet.

Year of birth was included as a fixed effect in the model for all three wool traits. Because animals could have more than one measurement for fleece weight and fleece grade, the additional fixed effect of age (years) at shearing was added to the model for these two traits. Julian day of year shorn was included as a linear covariate for all three wool traits.

\section{Two-Trait Analyses}

Traits were analyzed by pairs to estimate covariance components. In addition to (co)variance structures for single-trait models, covariances between the two traits depended on the models for the traits (Table 4). For two-trait analyses for litter size at weaning with each of the wool traits, the fixed effect of number of lambs weaned included in the model for wool traits was dropped from the model due to apparent confounding with the litter size weaned trait.

Correlations between permanent environmental effects were estimated between prolificacy traits and wool traits recorded in the same year of production. To estimate environmental correlations between an animal's own birth weight, weaning weight, and yearling staple length and her prolificacy and wool traits,

Table 4. Description of fixed and random factors in animal models associated with prolificacy, weight, and wool traits

\begin{tabular}{|c|c|c|c|}
\hline Trait & Fixed factors & Random factors & Covariate \\
\hline Litter size at birth & $\begin{array}{l}\text { Year of reproduction } \\
\text { Age of ewe (year) }\end{array}$ & $\begin{array}{c}\text { Direct genetic (ewe) } \\
\text { Permanent environmental (ewe) }\end{array}$ & \\
\hline Birth weight, kg & $\begin{array}{l}\text { Year of birth } \\
\text { Age of dam (year) } \\
\text { Gender of lamb } \\
\text { Type of birth }\end{array}$ & $\begin{array}{c}\text { Direct genetic (lamb) } \\
\text { Maternal genetic (dam) } \\
\text { Permanent environmental (dam) }\end{array}$ & \\
\hline Weaning weight, $\mathrm{kg}$ & $\begin{array}{c}\text { Year of birth } \\
\text { Age of dam (year) } \\
\text { Gender of lamb } \\
\text { Type of birth and rearing }\end{array}$ & $\begin{array}{c}\text { Direct genetic (lamb) } \\
\text { Maternal genetic (dam) } \\
\text { Permanent environmental (dam) }\end{array}$ & \\
\hline Staple length, cm & $\begin{array}{c}\text { Year of production } \\
\text { Number of lambs weaned }\end{array}$ & Direct genetic (ewe lamb) & Day of year shorn \\
\hline
\end{tabular}


a permanent environmental effect was included in the model for birth weight, weaning weight and yearling staple length. This assignment of a permanent environmental effect to those traits, which were measured only once for each animal, was done to force the covariance between environmental effects into the covariance between permanent environmental effects rather than to the covariance between residual effects when one of the traits was measured more than once. Although the environmental covariance across traits can be forced into permanent environmental effects, interpretation requires some caution when one trait, such as birth weight, cannot have repeated measures (Okut et al., 1999). Because of the complete confounding between the permanent environmental and residual effects, variance due to those effects can go to either component of variance, which also makes interpretation of correlations among permanent environmental effects difficult (Bromley et al., 2000). The environmental variance for the single measured trait was calculated by summing variance components for permanent environmental and residual effects. The environmental correlation between traits was calculated with the formula presented by Okut et al. (1999). For pairs of traits measured in the same year for each ewe (litter size at birth, litter size at weaning, fleece weight, and fleece grade), covariances between both permanent and temporary environment effects were estimated from bivariate analyses.

A derivative-free REML algorithm (DFREML, Graser et al., 1987) using computer programs of Boldman et al. (1995) was used for estimating (co)variance components. Local convergence was considered attained when the variance of the $-2 \log$ likelihoods in the simplex was less than $10^{-6}$. Global convergence was considered attained when the -2 log likelihoods did not change to the third decimal after restarting.

\section{Seven-Trait Analysis}

Estimates of (co)variances from single-trait analyses and estimates of correlations from two-trait analyses were used to set up mixed-model equations to estimate breeding values for the seven traits simultaneously. A $9 \times 9$ genetic (co)variance matrix and an 11 $\times 11$ environmental (co)variance matrix were constructed. There were two types of permanent environmental covariances between traits included in the environmental (co)variance matrix. The first type was the permanent environmental covariance estimated from traits with repeated records. The second type was where the permanent environmental effect was completely confounded with the temporary environmental (or residual) effect because the trait was measured only once. Because the variance due to the permanent environmental and residual effects can go to either component of variance, a fraction of the total environmental variance (0.0001) was arbitrarily assigned to the residual variance for traits measured only once, and the remainder was assigned to the permanent environmental variance.

Because a (co)variance matrix must be positive definite, a singular value decomposition was applied to each of the two matrices as follows:

$$
\mathbf{V}=\mathbf{P D P}^{\prime}
$$

where $\mathbf{V}$ is either the genetic or environmental (co)variance matrix, $\mathbf{D}$ is a diagonal matrix of eigenvalues, and $\mathbf{P}$ is a matrix of eigenvectors. Any eigenvalue in $\mathbf{D}$ that was negative was replaced with a small positive value $(0.0001)$ to create a modified diagonal matrix, D*. A new (co)variance matrix was then calculated as

$$
\mathbf{V}^{*}=\mathbf{P D} * \mathbf{P}^{\prime}
$$

where $\mathbf{V}^{*}$ is positive definite.

\section{Results and Discussion}

\section{Estimates from Single-Trait Analyses}

Estimates of genetic parameters for prolificacy, weight, and wool traits from single-trait analyses are in Table 5.

Prolificacy Traits. Heritability estimates for the prolificacy traits were small, 0.09 for litter size at birth and 0.06 for litter size at weaning. Fractions of variance due to permanent environmental effects of the ewe were also small, 0.03, for both traits. Estimates of heritability were similar to those reported by Bromley et al. (2000) of 0.07 for lambs born per parturition (lambs born) and 0.03 for lambs weaned per parturition (lambs weaned). Fractions of variance due to permanent environmental effects that they reported were also small (0.03 for lambs born and 0.07 for lambs weaned). For lambs born, de Vries et al. (1998) reported similar estimates for both heritability (0.10) and fraction of variance due to permanent environmental effects for the Swifter breed (0.02), a synthetic breed developed for high fecundity and improved meat production. Fogarty (1995), in a review, reported a weighted mean of estimates of heritability for litter size at birth to be 0.08. Burfening et al. (1993) reported an estimate of heritability (0.11) for litter size at birth for Rambouillet ewes managed under Western mountain range conditions. Sakul et al. (1999) reported a lower estimate of realized heritability (0.011) and a similar mixed-model estimate of heritability (0.09) for lambs born for grade Targhee ewes managed in a range environment. The heritability estimate for litter size at weaning is similar to the realized heritability estimate (0.02) for survival to weaning reported by Bradford et al. (1999) for the same grade Targhee ewes used in Sakul et al. (1999). The heritability estimate for litter size at weaning is similar to the estimate of 0.04 reported by Burfening et al. (1993) for Rambouillet ewes and to the weighted mean of reported estimates of 0.05 reported by Fogarty (1995). 
Table 5. Estimates of genetic parameters ${ }^{\mathrm{a}}$ and SE from single-trait analyses

\begin{tabular}{|c|c|c|c|c|c|c|}
\hline \multicolumn{7}{|l|}{ Prolificacy traits (trait of ewe) } \\
\hline Litter size at birth & $0.09 \pm 0.01$ & $\mathrm{ND}^{\mathrm{b}}$ & $\mathrm{ND}^{\mathrm{b}}$ & $0.89 \pm 0.01$ & $0.03 \pm 0.01$ & 0.412 \\
\hline \multicolumn{7}{|l|}{ Weight traits (trait of lamb) } \\
\hline Birth weight, kg & $0.27 \pm 0.02$ & $0.25 \pm 0.02$ & $-0.05 \pm 0.05$ & $0.45 \pm 0.01$ & $0.05 \pm 0.01$ & 0.538 \\
\hline Weaning weight, $\mathrm{kg}$ & $0.16 \pm 0.02$ & $0.08 \pm 0.01$ & $0.35 \pm 0.10$ & $0.68 \pm 0.01$ & $0.03 \pm 0.01$ & 27.6 \\
\hline Fleece grade, spinning count & $0.41 \pm 0.02$ & $\mathrm{ND}^{\mathrm{b}}$ & $\mathrm{ND}^{\mathrm{b}}$ & $0.48 \pm 0.01$ & $0.11 \pm 0.01$ & 12.1 \\
\hline Staple length, cm & $0.55 \pm 0.04$ & $\mathrm{ND}^{\mathrm{b}}$ & $\mathrm{ND}^{\mathrm{b}}$ & $0.45 \pm 0.04$ & $\mathrm{ND}^{\mathrm{c}}$ & 1.14 \\
\hline
\end{tabular}

${ }^{a} h_{a}^{2}=$ direct heritability; $h_{m}^{2}=$ maternal heritability; $r_{a m}=$ correlation between direct and maternal genetic effects; $e^{2}=$ variance due to residual effects as proportion of total variance; $\mathrm{p}^{2}=$ variance due to permanent environmental effects associated with the animal as proportion of total variance, where the animal is the ewe for ewe traits and the dam for lamb traits; and $\sigma_{\mathrm{p}}^{2}=$ phenotypic variance.

${ }^{b}$ Maternal effects not included in the model for traits of the ewe.

'Permanent environmental effects not included for staple length because the trait was measured only once at 1 yr of age.

Weight Traits. The estimate of direct heritability for birth weight was moderate (0.27), but small for weaning weight $(0.16)$. The estimate of maternal heritability for birth weight was more than three times as large as for weaning weight ( $0.25 \mathrm{vs} 0.08)$. Estimates of genetic correlation between direct and maternal effects were small and negative for birth weight $(-0.05)$ and moderate and positive for weaning weight (0.35). Variance due to permanent environmental effects associated with the dam as a proportion of total variance was similar for birth weight (0.05) and for weaning weight (0.03). The estimate of direct heritability for birth weight was greater than the estimate $(0.18)$ reported by Bromley et al. (2000). However, the estimate of maternal heritability was similar to their estimate (0.24). Estimates of direct heritability for both birth weight and weaning weight were similar to the weighted mean of estimates ( 0.19 and 0.20 , respectively) for dual-purpose breeds reported by Fogarty (1995). The estimate of direct heritability for weaning weight was higher than the realized heritability estimates (0.06 and 0.08) reported by Sakul et al. (1999) but similar to their heritability estimate $(0.16)$ based on a mixed-model. The larger estimate of maternal heritability for birth weight compared with the estimate for weaning weight supports the conclusion of Robison (1981) that maternal genetic effects generally are important for measurements of weight at younger ages and diminish with increasing age. The estimates of direct and maternal heritabilities also agree with those of Näsholm and Danell (1994), who reported that maternal heritability estimates were higher than direct heritability estimates for lamb weights at early ages, but that at later ages direct heritability estimates were up to three times greater than estimates for maternal heritability.

Wool Traits. Estimates of direct heritability for wool traits were moderate to large $(0.53,0.41$, and 0.55 , for fleece grade, fleece weight, and staple length, respectively). Estimates of variance due to permanent environmental effects as a proportion of total variance were 0.14 for fleece weight and 0.11 for fleece grade. Heritability estimates for fleece weight and staple length agreed with estimates of 0.47 and 0.44 , respectively, reported by Bromley et al. (2000). The estimate for fleece weight was larger than the weighted mean of 0.36 summarized by Fogarty (1995), but smaller than the 0.66 reported by Saboulard et al. (1995) for clean fleece weight in Western Whiteface ewes. The estimate for fleece grade was somewhat less than the estimate of 0.46 reported by Bromley et al. (2000) and was also smaller than the weighted mean of 0.52 reported for fiber diameter by Fogarty (1995). The estimate of variance due to permanent environmental effects as a proportion of total variance for fleece weight was similar to the 0.13 reported by Bromley et al. (2000).

\section{Estimates from Bivariate Analyses}

Within Prolificacy Traits. The estimate of direct genetic correlation between litter size at birth and litter

Table 6. Estimates of genetic parameters ${ }^{\mathrm{a}}$ from bivariate analysis for litter size at birth and litter size at weaning

\begin{tabular}{|c|c|c|c|c|c|c|c|c|c|c|c|c|}
\hline Litter size at birth, $\mathrm{n}$ & Litter size at weaning, $\mathrm{n}$ & 0.09 & 0.06 & 0.84 & 0.03 & 0.03 & 0.52 & 0.89 & 0.91 & 0.59 & 0.412 & 0.410 \\
\hline
\end{tabular}

\footnotetext{
${ }^{a} h_{i}^{2}=$ direct heritability for trait $i ; r_{g}=$ genetic correlation; $p_{i}^{2}=$ variance due to permanent environmental effects associated with the animal as proportion of total variance for trait $\mathrm{i} ; \mathrm{r}_{\mathrm{p}}=$ correlation between permanent environmental effects; $\mathrm{e}_{\mathrm{i}}^{2}=$ variance due to residual effects as proportion of total variance for trait $\mathrm{i} ; \mathrm{r}_{\mathrm{e}}=$ correlation between temporary environmental effects; and $\sigma_{\mathrm{i}}=$ phenotypic variance for trait $\mathrm{i}$.
} 
Table 7. Estimates of genetic parameters ${ }^{\mathrm{a}}$ from bivariate analysis for birth and weaning weights

\begin{tabular}{lccc}
\hline \hline Parameter & Birth weight, kg & Correlations & Weaning weight, kg \\
\hline $\mathrm{h}^{2}{ }_{\mathrm{a}}$ & 0.27 & & 0.16 \\
$\mathrm{~h}^{2}{ }_{\mathrm{m}}$ & 0.25 & & 0.09 \\
$\mathrm{r}_{\mathrm{am}}$ & -0.03 & & 0.34 \\
$\mathrm{p}^{2}{ }_{\mathrm{m}}$ & 0.05 & & 0.03 \\
$\mathrm{e}^{2}{ }_{\sigma_{\mathrm{p}}}{ }_{\mathrm{p}}$ & 0.44 & & 0.68 \\
$\mathrm{r}_{\mathrm{g}}$ & 0.541 & 0.56 & 27.7 \\
$\mathrm{r}_{\mathrm{m}}$ & & 0.58 & \\
$\mathrm{r}_{\mathrm{alm} 2}$ & & 0.00 & \\
$\mathrm{r}_{\mathrm{a} 2 \mathrm{~m} 1}$ & & 0.23 & \\
$\mathrm{r}_{\mathrm{p}}$ & & 0.46 & \\
$\mathrm{r}_{\mathrm{e}}$ & & 0.33 & \\
\hline
\end{tabular}

${ }^{\mathrm{a}} \mathrm{h}^{2}=$ direct heritability; $\mathrm{h}_{\mathrm{m}}^{2}=$ maternal heritability; $\mathrm{p}_{\mathrm{m}}^{2}=$ variance due to permanent environmental effects associated with the dam as proportion of total variance; $\mathrm{e}^{2}=$ variance due to residual effects as proportion of total variance; $\sigma^{2}=$ phenotypic variance; $\mathrm{r}_{\mathrm{am}}=$ correlation between direct additive genetic and maternal additive genetic effects within trait; $r_{g}=$ genetic correlation; $r_{m}=$ correlation between maternal genetic effects; $r_{p}=$ correlation between maternal permanent environmental effects; $r_{e}=$ correlation between temporary environmental effects; and $\mathrm{r}_{\mathrm{aimj}}=$ correlation between direct additive genetic effect for trait $\mathrm{i}$ and maternal genetic effect for trait $\mathrm{j}$.

size at weaning was large and positive (0.84; Table 6$)$. The estimate of the genetic correlation between litter size at birth and litter size at weaning was less than the 1.00 estimated by Bromley et al. (2000), which may be due to inclusion in the current study of records of all ewes that were bred and present at lambing and of records of ewes lambing with lambs dead at birth. The estimate of genetic correlation was less than the weighted average of 0.91 from the review of Fogarty (1995).

The estimate of correlation between permanent environmental effects of ewes was moderate and positive for litter size at birth with litter size at weaning (0.52). This estimate was larger than the estimate of 0.22 presented by Bromley et al. (2000). Differences between this study and that of Bromley et al. (2000) may be due largely to our consideration of nonpregnant ewes at lambing, whereas Bromley et al. (2000) considered only records of ewes that lambed with live lambs.

Within Weight Traits. As shown in Table 7, the estimate of direct genetic correlation between birth weight and weaning weight was moderate and positive (0.56), which was greater than the 0.18 between birth weight and average daily gain from birth to weaning reported by Bromley et al. (2000) and the weighted mean of 0.39 between birth weight and weaning weight summarized by Fogarty (1995). The moderate estimate of direct genetic correlation between birth weight and weaning weight suggests that animals with above average weaning weight would tend to be above average in genetic merit for birth weight. The estimate of maternal genetic correlation between birth weight and weaning weight was also moderately positive (0.58) and was larger than the estimate of 0.38 presented by Bromley et al. (2000). The moderately positive maternal genetic correlation indicates that Columbia ewes, which are above average in genetic merit for giving birth to lambs with heavier birth weights, will tend to produce lambs with heavier weaning weights. Estimates of genetic correlations between direct and maternal effects were both small to moderate $(0.00$ and 0.23 ) and were in general agreement with estimates presented by Bromley et al. (2000). The estimate of correlation between permanent environmental effects of the dam for birth and weaning weight was moderately large and positive $(0.46)$ and agreed with the estimate between birth weight and average daily gain to weaning of 0.46 reported by Bromley et al. (2000).

Within Wool Traits. Table 8 shows that estimates of direct genetic correlations between pairs of wool traits were positive between fleece weight and staple length (0.55) and negative between fleece grade and both fleece weight $(-0.47)$ and staple length $(-0.70)$, which agree with previous estimates (Bromley et al., 2000).

The moderate and negative (unfavorable) estimate of the genetic correlation between fleece grade and fleece weight is larger than the small and positive (unfavorable) mean of estimates (0.17) between fleece fiber diameter and fleece weight reported by Fogarty (1995), but similar to the moderate and positive (unfavorable) genetic correlation between fiber diameter and clean fleece weight (0.36) reported by Iman et al. (1992). The negative genetic correlation between fleece weight and grade suggests that selection for fleece weight would decrease genetic merit for fleece grade. The large positive estimate of genetic correlation $(0.55)$ between fleece weight and staple length is larger than the estimate of 0.20 between yearling fleece weight and staple length reported for Merino sheep by Atkins (1997). The positive genetic correlation indicates that staple length would increase as a genetic response to selection for increased fleece weight. The large negative estimate of genetic correlation $(-0.70)$ 
Table 8. Estimates of genetic parameters from bivariate analyses for fleece weight, fleece grade, and staple length

\begin{tabular}{|c|c|c|c|c|c|c|c|c|c|c|c|c|}
\hline Fleece weight, $\mathrm{kg}$ & Fleece grade, count & 0.53 & 0.42 & -0.47 & 0.14 & 0.11 & -0.43 & 0.33 & 0.48 & -0.16 & 0.831 & 12.1 \\
\hline Fleece weight, kg & Staple length, cm & 0.53 & 0.55 & 0.55 & 0.14 & $\mathrm{ND}^{\mathrm{b}}$ & $\mathrm{ND}^{\mathrm{b}}$ & 0.33 & 0.45 & 0.20 & 0.833 & 1.17 \\
\hline
\end{tabular}

${ }^{a} h_{i}^{2}=$ direct heritability for trait $\mathrm{i} ; \mathrm{r}_{\mathrm{g}}=$ genetic correlation; $\mathrm{p}_{\mathrm{i}}^{2}=$ variance due to permanent environmental effects associated with the animal as proportion of total variance for trait $i ; r_{p}=$ correlation between permanent environmental effects; $e_{i}^{2}=$ variance due to residual effects as proportion of total variance for trait $\mathrm{i} ; \mathrm{r}_{\mathrm{e}}=$ correlation between temporary environmental effects; and $\sigma_{\mathrm{i}}^{2}=$ phenotypic variance for trait i.

${ }^{b}$ Permanent environmental effects not included for staple length because the trait was measured only once at $1 \mathrm{yr}$ of age.

between fleece grade and staple length is much greater in magnitude than the estimate of 0.10 between fiber diameter and staple length reported by Atkins (1997). The negative genetic correlation between fleece grade and staple length indicates that staple length would decrease as a genetic response to increase (improvement) in fleece grade.

Prolificacy and Weight Traits. Estimates of genetic correlations among prolificacy and weight traits ranged from 0.00 between litter size at weaning and birth weight to 0.33 between litter size at birth and weaning weight (Table 9). The estimate of genetic correlation between litter size at weaning and birth weight was different from the -0.37 reported for the Columbia breed by Bromley et al. (2000). The estimate of the genetic correlation between birth weight and litter size at birth (0.10) was similar to the average for four breeds of 0.12 reported by Bromley et al. (2000), but was smaller than the average of estimates (0.30) reviewed by Fogarty (1995).

Estimates of genetic correlation between weaning weight and litter size at birth (0.33) and weaning weight and litter size at weaning $(0.24)$ were in agreement with the average for three breeds (Polypay, Rambouillet, and Targhee) reported by Bromley et al. (2000) for average daily gain to weaning and litter size at birth (0.31) and for average daily gain to weaning and litter size at weaning $(0.14)$, but conflict with those reported for Columbia sheep in the same study $(-0.30$ for average daily gain to weaning and litter size at birth and -0.82 for average daily gain to weaning and litter size at weaning). Fogarty (1995) reported a mean of estimates of genetic correlation between weaning weight and litter size at weaning of 0.34 . Positive correlations suggest selection for weaning weight may increase genetic merit for litter size at birth.

Estimates of correlations between direct genetic effects for prolificacy traits and maternal genetic effects for weight traits were moderate to large. The estimate between litter size at birth and weaning weight $(0.40)$ and litter size at weaning and birth weight $(0.36)$ were larger than estimates of 0.02 and 0.08 , respectively, reported by Bromley et al. (2000), but the estimates between litter size at birth and birth weight $(0.21)$ and litter size at weaning and weaning weight $(0.66)$ were similar to their estimates ( 0.36 and 0.51 , respectively).
Prolificacy and Wool Traits. Estimates of genetic correlations between prolificacy traits and wool traits ranged from -0.20 between litter size at weaning and staple length to 0.17 between litter size at birth and fleece grade (Table 10). These estimates in general were in the same direction, but smaller in magnitude than those estimated by Bromley et al. (2000). One exception was between litter size at birth and fleece grade, where they reported a genetic correlation of -0.02 . Small negative correlations between fleece weight and the litter size traits indicate ewes that are genetically predisposed to produce larger litters also tend to produce lighter fleeces. Ewes with higher reproductive rates may genetically partition more nutritional resources away from wool fiber growth in favor of reproduction. Slightly positive (desirable) genetic correlations between fleece grade and the two litter size traits indicate that selecting for increased litter size should not have a negative impact on fleece grade. Staple length as yearlings, however, was negatively correlated with both prolificacy traits. The negative correlations may indicate that animals that are genetically predisposed to producing and weaning smaller litters are also genetically predisposed to divert available nutritional resources into production of wool.

Estimates of correlations between permanent environmental effects for prolificacy and wool traits ranged from -0.63 between litter size at birth and fleece grade and 0.51 between litter size at birth and fleece weight. Environmental effects associated with the ewe's lifetime records appear to have either significant positive or negative effects on the relationship between litter size at birth and some fleece characteristics.

Weight and Wool Traits. Estimates of genetic correlations ranged from -0.11 between weaning weight and fleece grade to 0.21 between birth weight and fleece weight (Table 11), similar to those reported by Bromley et al. (2000). Positive correlations for fleece weight with birth and weaning weight $(0.21$ and 0.18$)$ suggest genetic factors influencing animal growth also influence wool growth.

\section{Estimates of Individual Breeding Values and Genetic Change}

Means of estimates of breeding value by year of birth calculated from both single-trait analyses and from 


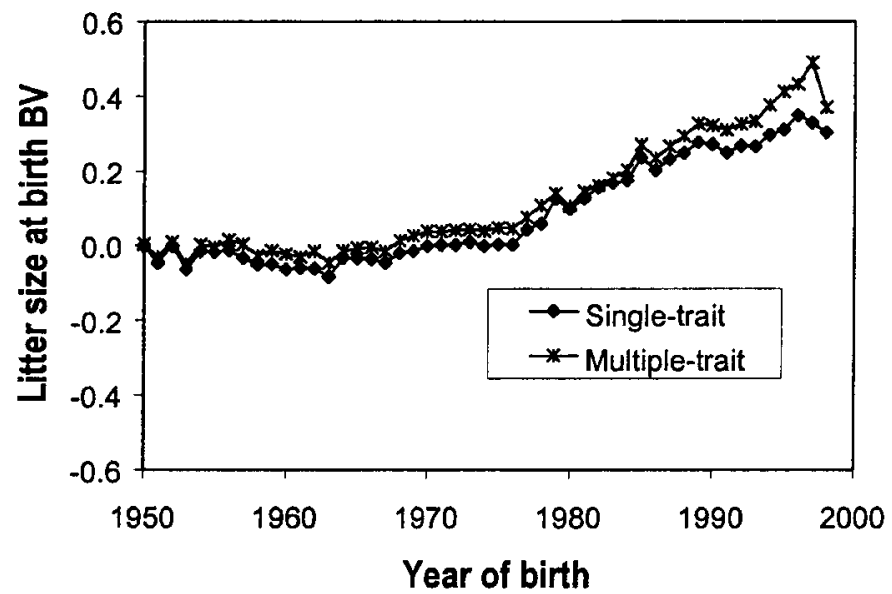

Figure 1. Means of estimates of breeding value for litter size at birth by year of birth from single- and multipletrait analyses.

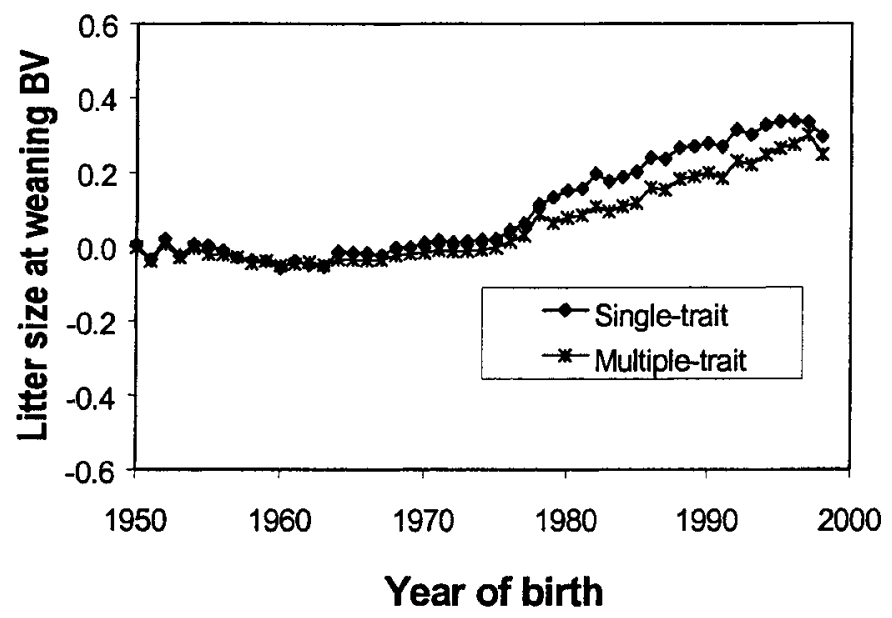

Figure 2. Means of estimates of breeding value for litter size at weaning from single- and multiple-trait analyses by year of birth.

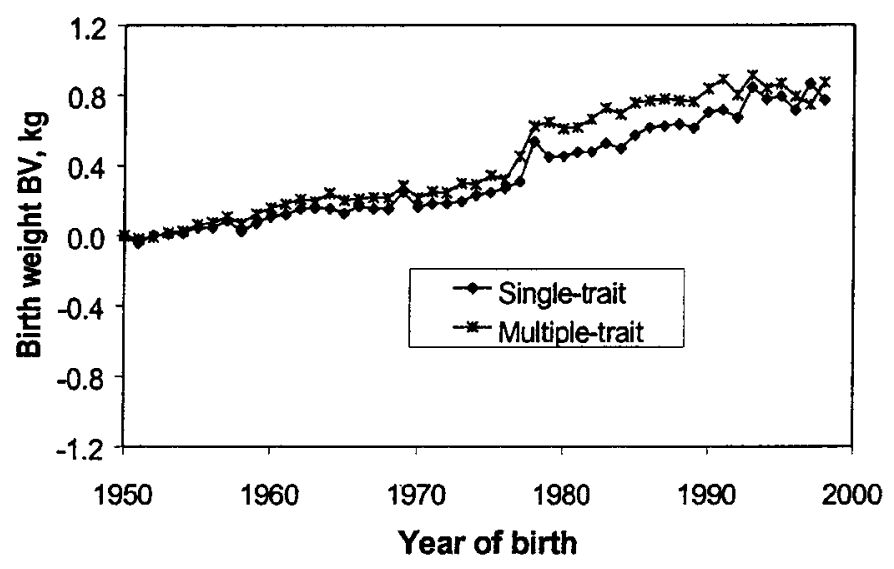

Figure 3. Means of estimates of breeding value for birth weight of lambs by year of birth from single- and multiple-trait analyses. 


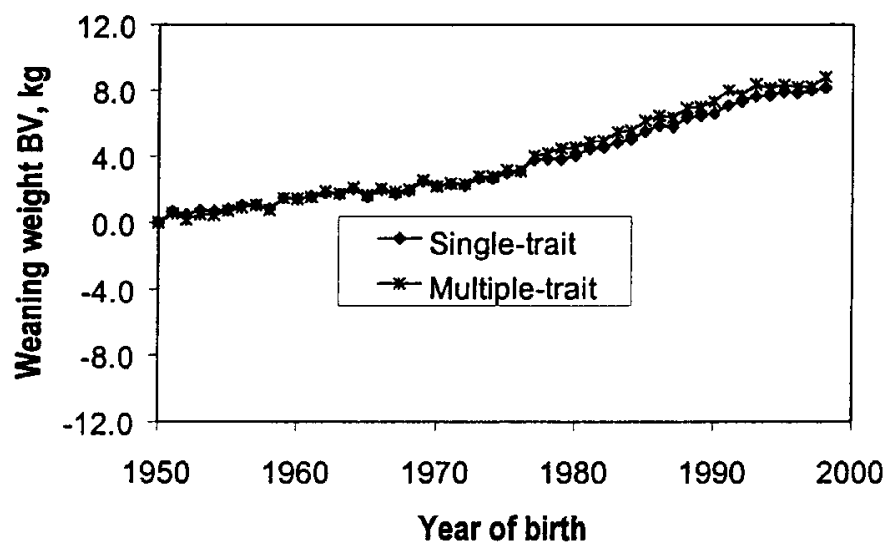

Figure 4. Means of estimates of breeding value for weaning weight of lambs by year of birth from singleand multiple-trait analyses.

the seven-trait analysis are plotted in Figures 1 and 2 for prolificacy traits, in Figures 3 and 4 for weight traits, and in Figures 5 through 7 for wool traits. Means of estimates of breeding value by year are deviations from the means of estimates of breeding value for animals born in 1950 (1977 for staple length).

Prolificacy Traits. Means of estimates of breeding value by year of birth for litter size at birth from the single-trait analysis and the multiple trait analysis over time were similar (Figure 1). The mean estimates for litter size at birth increased about 0.4 lambs from 1950 to 1998.

Means of estimates of breeding value by year of birth for litter size at weaning from the single-trait and the multiple-trait analyses also were similar from 1950 to 1978 (Figure 2). Between 1977 and 1978, means of estimates of breeding value from both single-trait and multiple-trait analyses increased by almost 0.1 lamb.

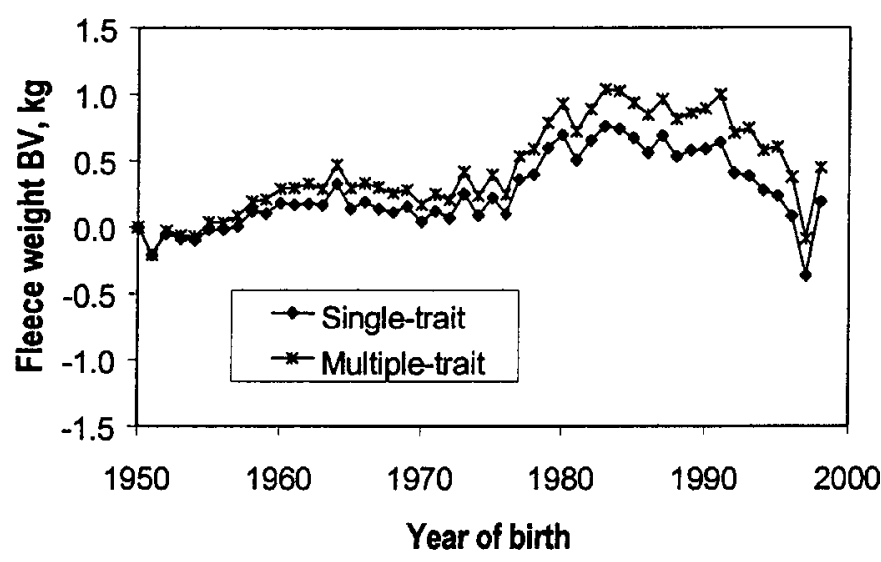

Figure 5. Means of estimates of breeding value for fleece weight of ewes and ewe lambs from single- and multipletrait analyses by year of birth.

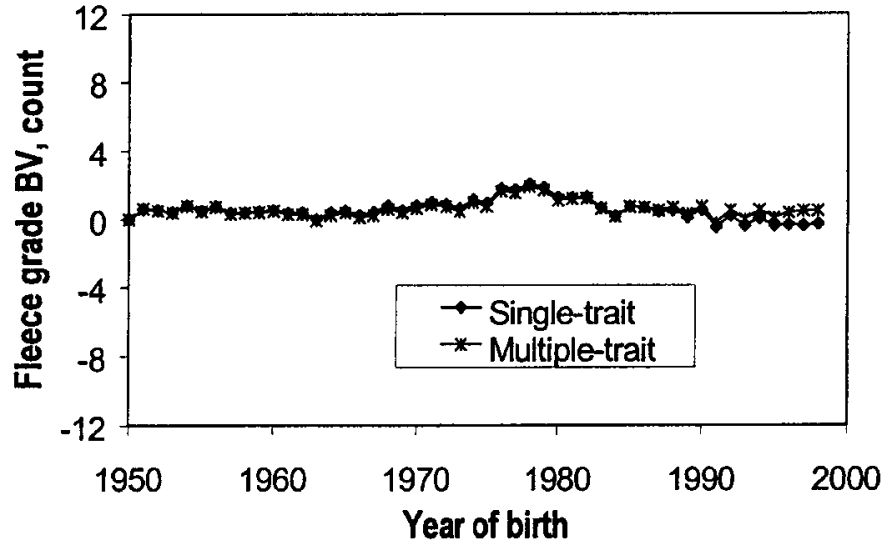

Figure 6. Means of estimates of breeding value for fleece grade of ewes and ewe lambs from single- and multipletrait analyses by year of birth.

From 1979 to 1996, means of estimates of breeding value from the single-trait analysis were about 0.1 lamb greater each year than estimates from the multiple-trait analysis. The start of the divergence coincided with the introduction of outside rams for the 1977 and 1978 breeding seasons (siring about $75 \%$ and $20 \%$ of the lamb in 1978 and 1979, respectively). The divergence may be due partly to means of estimates of breeding value for weaning weight (which was positively correlated to litter size at weaning) not changing between 1977 and 1979 and thus causing multipletrait estimates for litter size at weaning to be smaller than single-trait estimates. The mean of estimates of breeding value for litter size at weaning increased by 0.3 lamb during the study period, which was slightly smaller than the increase for litter size at birth.

Weight Traits. Means of estimates of breeding value for birth weight by year of birth from the single-trait

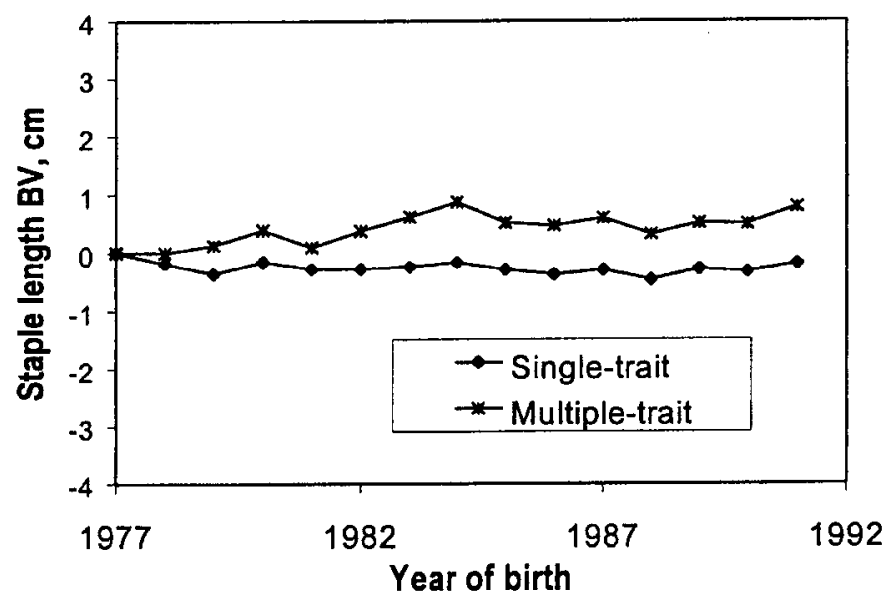

Figure 7. Means of estimates of breeding value for staple length of ewe lamb fleeces from single- and multipletrait analyses. 
Table 10. Estimates of genetic parameters ${ }^{\mathrm{a}}$ from bivariate analyses between prolificacy and wool traits

\begin{tabular}{|c|c|c|c|c|c|c|c|c|c|c|c|c|}
\hline Litter size at birth & Fleece weight, $\mathrm{kg}$ & 0.09 & 0.53 & -0.13 & 0.03 & 0.14 & 0.51 & 0.89 & 0.33 & -0.11 & 0.413 & 0.834 \\
\hline Litter size at birth & Fleece grade, count & 0.09 & 0.47 & 0.17 & 0.03 & 0.07 & -0.63 & 0.89 & 0.45 & 0.05 & 0.412 & 13.0 \\
\hline Litter size at weaning & Fleece weight, kg & 0.06 & 0.53 & -0.14 & 0.03 & 0.14 & 0.22 & 0.91 & 0.33 & -0.03 & 0.410 & 0.834 \\
\hline Litter size at weaning & Fleece grade, count & 0.06 & 0.41 & 0.04 & 0.03 & 0.11 & -0.09 & 0.91 & 0.48 & -0.01 & 0.410 & 12.1 \\
\hline Litter size at weaning & Staple length, cm & 0.06 & 0.56 & -0.20 & 0.03 & $\mathrm{ND}^{\mathrm{b}}$ & $\mathrm{ND}^{\mathrm{b}}$ & 0.91 & 0.44 & 0.03 & 0.410 & 1.14 \\
\hline
\end{tabular}

${ }^{\mathrm{a}} \mathrm{h}^{2}=$ direct heritability for trait $\mathrm{i} ; \mathrm{r}_{\mathrm{g}}=$ genetic correlation; $\mathrm{p}_{\mathrm{i}}^{2}=$ variance due to permanent environmental effects associated with the animal as proportion of total variance for trait $i ; r_{p}=$ correlation between permanent environmental effects; $e_{i}^{2}=$ variance due to residual effects as proportion of total variance for trait $\mathrm{i} ; \mathrm{r}_{\mathrm{e}}=$ correlation between temporary environmental effects; and $\sigma_{\mathrm{i}}^{2}=$ phenotypic variance for trait i.

${ }^{\mathrm{b}}$ Permanent environmental effects not included for staple length because the trait was measured only once at $1 \mathrm{yr}$ of age.

analysis were slightly less from 1958 to 1976 than means of estimates for breeding value from the multiple-trait analysis (Figure 3). During that period, the average estimate of breeding value for birth weight increased $0.3 \mathrm{~kg}$. The mean of estimates of breeding value for birth weight increased more than $0.2 \mathrm{~kg}$ between 1977 and 1978. After 1978 and until 1992, means of estimates of breeding value from the singletrait analysis were about $0.2 \mathrm{~kg}$ less than means of estimates of breeding value from the multiple-trait analysis. Selection was not directly applied for birth weight. The $0.2-\mathrm{kg}$ difference between the two means of estimates of breeding value for birth weight may be due to the positive genetic correlations between birth weight and litter size at birth and also weaning weight. The difference between means of estimates of breeding value from single-trait and multiple-trait analyses decreased after 1992. Means of estimates of breeding value for birth weight increased about 0.8 $\mathrm{kg}$ during the study period.

Means of estimates of breeding value for weaning weight by year of birth from single-trait and multipletrait analyses were similar from 1950 to 1976 during which both increased about $3 \mathrm{~kg}$ (Figure 4 ). The increase in means of estimates of breeding value between 1976 and 1977 was $1 \mathrm{~kg}$. From 1978 to 1998, the means of estimates of breeding value increased steadily, a total of about $4 \mathrm{~kg}$. Estimates from the single-trait analysis were slightly smaller than estimates from the multiple-trait analysis during this period. Weaning weight was positively correlated genetically with litter size at birth (0.33), litter size at weaning (0.24), and birth weight (0.56). These three traits all increased during the study period. Because the multiple-trait analysis accounts for correlations among weaning weight and the other three traits, the increase in the three correlated traits may have resulted in larger estimates of breeding value from the multiple-trait analysis than those from single-trait analyses, which do not take into account correlations among traits. During the $49-\mathrm{yr}$ period, the mean of estimates of breeding value by year of birth for weaning weight increased over $8 \mathrm{~kg}$.

Wool Traits. Means of estimates of breeding value for fleece weight by year of birth from single-trait and multiple-trait analyses showed a fairly consistent pattern with means of estimates from the multiple-trait analysis being higher than means of estimates from the single-trait analysis (Figure 5). Larger means of estimates of breeding value from the multiple-trait analysis may be due to the large negative genetic correlation of -0.47 between fleece weight and fleece grade and small positive correlations between fleece weight and both birth weight $(0.21)$ and weaning weight (0.18). Means of estimates of breeding value for fleece weight increased over $0.3 \mathrm{~kg}$ from 1954 to 1963. Means of estimates of breeding value varied between 0.3 and $0.5 \mathrm{~kg}$ greater than the base year (1950) from 1964 to 1977 . The introduction of the outside rams appeared to cause means of estimates of breeding value to increase another $0.4 \mathrm{~kg}$ from 1978 to 1980 . Means of estimates of breeding value then varied between 0.7 and $1.0 \mathrm{~kg}$ heavier than the base year until about 1993, when means of estimates of breeding value decreased to $0.3 \mathrm{~kg}$ below the base year estimates by 1997, although rebounding to $0.3 \mathrm{~kg}$ above the base year estimates in 1998. However, the animals born in 1998 had no fleece records, so that their estimates of breeding value are based on records of ancestors, which were mostly born in 1996 and earlier, before the 1997 decrease in the mean of estimates of breeding value.

Means of estimates of breeding value by year of birth for fleece grade were similar between single-trait and multiple-trait analyses (Figure 6) and changed little from the base year through 1967. From 1967 until 1978 , means of estimates of breeding value gradually increased by 2 spinning counts. From 1978 to about 1990 means of estimates of breeding value gradually decreased toward the mean for the base year. Means of estimates of breeding value were similar to those for the base year for the remainder of the study period. Means of breeding values by year of birth from singletrait and multiple-trait analyses were within 1 spinning count throughout the study, which is a small difference considering the standard deviation of 3.8.

Means of estimates of breeding value by year of birth for staple length from the single-trait analysis decreased about $0.2 \mathrm{~cm}$ over $13 \mathrm{yr}$, but means of estimates of breeding value from the multiple-trait analy- 
sis showed an increase of about $0.8 \mathrm{~cm}$ (Figure 7). The difference in means was established by 1982 to 1983 and remained constant to 1991. This difference may be due to the high positive genetic correlation between staple length and fleece weight. The mean of estimates of breeding value for fleece weight increased almost 1 $\mathrm{kg}$ during the same time period. Traits with which staple length is negatively correlated did not show any substantial increase between 1977 and 1990 and so would not have as much influence as fleece weight on estimates of breeding value from the multiple-trait analysis for staple length.

Estimated breeding values averaged over year of birth did not appear to differ substantially between estimates of breeding values obtained from singletrait and multiple-trait analyses, except for traits which were highly correlated with another trait that was responding to selection. Estimates of breeding value for litter size at birth and litter size at weaning from the multiple-trait analysis tended to be higher relative to estimates from single-trait analyses due to the high genetic correlation between them (0.79). Estimates of breeding value for birth weight and weaning weight from the multiple-trait analysis also increased relative to estimates from single-trait analyses due to the high genetic correlation between them (0.56). Use of estimates of genetic correlations less than 0.5 did not have a noticeable impact on breeding value estimates of other traits.

\section{Implications}

Litter size at weaning and weaning weight are both components of weaning performance, an economically important trait, and are lowly heritable. However, selection based on weaning performance over a long period could result in a moderate positive response in both litter size at weaning and weaning weight in a flock of a dual-purpose breed, such as the Columbia. Although, litter size at birth and birth weight are also lowly heritable, positive genetic correlations between the components of weaning performance with both of these traits suggest that selecting for weaning performance would result in positive genetic gains in both litter size at birth and birth weight. Wool traits would not be expected to be adversely affected significantly over a long period of selection for weaning performance, due to the near zero genetic correlations between weaning performance and wool traits.

\section{Literature Cited}

Atkins, K. D. 1997. Genetic improvement of wool production. Pages 471-504 in The Genetics of Sheep. L. Piper and A. Ruvinsky, ed. CAB International, Oxon, U.K.

Boldman, K. G., L. A. Kriese, L. D. Van Vleck, C. P. Van Tassell, and S. D. Kachman. 1995. A manual for the use of MTDFREML. A set of Programs to Obtain Estimates of Variances and Covariances [DRAFT]. ARS-USDA, Clay Center, NE.

Bradford, G. E., H. Sakul, and M. R. Dally. 1999. Selection for weaning weight or litter size in range sheep: II. Correlated 
responses and effect on productivity. Sheep and Goat Res. J. 15:138-146.

Bromley, C. M., G. D. Snowder, and L. D. Van Vleck. 2000. Genetic parameters among weight, prolificacy, and wool traits of Columbia, Polypay, Rambouillet, and Targhee sheep. J. Anim. Sci. 78:846-858.

Burfening, P. J., S. D. Kachman, K. J. Hanford, and D. Rossi. 1993. Selection for reproductive rate in Rambouillet sheep: Estimated genetic change in reproductive rate. Small Ruminant Res. 10:317-330.

de Vries, M. J., E. H. van der Waaij, and J. A. M. van Arendonk. 1998. Estimation of genetic parameters for litter size in sheep: A comparison of a repeatability and a multivariate model. Anim. Sci. 66:685-688.

Ercanbrack, S. K., and A. D. Knight. 1981. Weaning trait comparisons among inbred lines and selected noninbred and randomly bred control groups of Rambouillet, Targhee and Columbia sheep. J. Anim. Sci. 52:977-988.

Ercanbrack, S. K., and A. D. Knight. 1998. Responses to various selection protocols for lamb production in Rambouillet, Targhee, Columbia, and Polypay Sheep. J. Anim. Sci. 76:1311-1325.

Fogarty, N. M. 1995. Genetic parameters for live weight, fat and muscle measurements, wool production and reproduction in sheep: A review. Anim. Breed. Abstr. 63:101-143.

Graser, H-U., S. P. Smith, and B. Tier. 1987. A derivative-free approach for estimating variance components in animal models by restricted maximum likelihood. J. Anim. Sci. 64:1362-1370.
Iman, N. Y., C. L. Johnson, W. C. Russell, and R. H. Stobart. 1992. Estimation of genetic parameters for wool fiber diameter measures. J. Anim. Sci. 70:1110-1115.

Lasslo, L. L., G. E. Bradford, D. T. Torell, and B. W. Kennedy. 1985. Selection for weaning weight in Targhee sheep in two environments. I. Direct response. J. Anim. Sci. 61:376-386.

Näsholm, A., and Ö. Danell. 1994. Maternal genetic effects on lamb weights. In: Proc. 5th World Cong. Genet. Appl. Livestock Prod., Guelph, Canada. 18:163-166.

Okut, H., C. M. Bromley, L. D. Van Vleck, and G. D. Snowder. 1999. Genotypic expression at different ages: I. Prolificacy traits of sheep. J. Anim. Sci. 77:2357-2365.

Pohle, E. M. 1963. Grading and production of wool. Pages 547-615 in Wool Handbook. W. von Bergen, ed. John Wiley \& Sons, New York.

Robison, O. W. 1981. The influence of maternal genetic effects on the efficiency of selection-A review. Livest. Prod. Sci. 8:121-137.

Saboulard, M., W. C. Russell, and M. L. Riley. 1995. Selection for lambing rate and clean fleece weight in sheep. J. Anim. Sci. 73:3195-3198.

Sakul, H., G. E. Bradford, and M. R. Dally. 1999. Selection for litter size or weaning weight in range sheep: I. Selection practiced and direct response. Sheep and Goat Res. J. 15:126-137.

Snowder, G. D., A. D. Knight, L. D. Van Vleck, C. M. Bromley, and T. R. Kellom. 2001. Usefulness of subjective ovine milk scores. I. Associations with range ewe characteristics and lamb production. J. Anim. Sci. 79:811-818. 